\title{
POST-TRAUMATIC STRESS DISORDER AFTER TERRORIST ATTACK IN HEALTHCARE PROFESSIONALS
}

\author{
Togay Evrin' ${ }^{1}$ Bulut Demirel ${ }^{2}$, Başak Yılmaz' ${ }^{1}$ Leyla Öztürk', Atila Korkmaz ${ }^{1}$, Erden Erol Unluer ${ }^{3}$, \\ Burak Katipoglu ${ }^{4}$, Refia Palabiyikoglu ${ }^{4}$, Sinan Cem Uzunget ${ }^{1}$, Ertugrul Kazancı ${ }^{1}$, Esra Bilge Derdiyok ${ }^{4}$ \\ 'Department of Emergency Medicine, UfuK University Medical Faculty, Dr Ridvan Ege Education and Research Hospital, Ankara, Turkey \\ ${ }^{2}$ Ankara Ataturk Training and Research Hospital Department of Emergency Medicine Ankara, Turkey \\ ${ }^{3}$ Emergency Department, Izmir Ataturk Research and Training Hospital, Izmir, Turkey \\ ${ }^{4}$ Department of Physiology, UfuK University Medical Faculty, Dr Ridvan Ege Education and Research Hospital Ankara, Turkey
}

\begin{abstract}
INTRODUCTION: On the date of 15 July 2016 a terrorist organization launched a terrorist attack using helicopters and heavy combat weapons in the city centers of Istanbul and Ankara simultaneously. Numerous civilian were hurt and many of them lost their lives during the attacks. Terrorism is a form of combat designed to cause the highest psychological influence on the masses. Post-traumatic stress disorder (PTSD) is one of the most common psychological disorders after such disasters. The aim of this study is to determine the associated risk factors and PTSD rates in healthcare professionals who were on call during the 15 July 2016 terrorist attacks.
\end{abstract}

METHOD: Since the hospital is in a neighbouring the street to where terror attacks occurred, all healthcare professionals $\geq 18$ years of age who were on duty that night in the Dr. Ridvan Ege Training and Research Hospital and were auditory or visual witnesses of the event were included in the study as the first group while healthcare professionals who work in the same hospital but were not on duty that night were included as the control group.

RESULTS: The mean post-traumatic diagnostic scale stress score of the control group was 11.87. The mean post-traumatic diagnostic scale stress score of the Group 1 was 21.91. There was a significant difference between the groups in terms of posttraumatic diagnostic scale stress score $(p<0.05)$. While the healthcare professionals on duty on July 15, 2016 (Group 1) had moderate-severe (21.91 \pm 5.11 ) stress disorder, the healthcare professionals who were not at the hospital on July 15, 2016 (Control Group) had moderate stress disorder (11.87 \pm 6.86$)$.

CONCLUSION: Our country is at risk from the fact that such attacks may be experienced again because of its unique conditions. The results of our work support the data on the high level of exposure to PTSD when exposed to a terrorist attack. For this reason, the identification of the characteristics of pre-traumatic health individuals at risk is useful in planning the presentation of preventive and curative health services. At the same time, there is a need for longer-term work and wider samples to reveal the psychological consequences of such attacks.

KEY WORDS: healthcare professional, PTSD, terrorist attack

Disaster Emerg Med J 2017; (2)1: 11-18

\section{INTRODUCTION}

On the date of 15 July 2016 a terrorist organization launched a terrorist attack using helicopters and heavy combat weapons in the city centers of Istan- bul and Ankara simultaneously. Numerous civilian were hurt and many of them lost their lives during the attacks. Terrorism is a form of combat designed to cause the highest psychological influence on the 
masses [1]. Post-traumatic stress disorder (PTSD) is one of the most common psychological disorders after disasters [2]. Many studies report that a high rate of PTSD is seen in people who have directly witnessed terrorist attacks [3]. The development of PTSD after terrorist attacks has been studied in countries such as Ireland, Israel, France, Tanzania [4], USA [5], Kenya [6] and Spain [7]. In some of these studies, risk factors for the development of PTSD in people who were exposed to trauma were investigated [4-7]. According to Frank et al. risk factors associated with PTSD were as follows: female gender, unmarried status, lack of college education, being outside during the blast, being a witness of the blast, being injured, not fully recovering from injury; bereavement; experiencing or anticipating financial difficulty after the blast, inability to work because of injury [6]. Even though Turkey has been exposed to this type of terrorist attacks in recent history and there are studies on how these attacks affect people psychologically, there are no studies regarding the development of PTSD in specific occupational groups. The aim of this study is to determine the associated risk factors and PTSD rates in healthcare professionals who were on call during the 15 July 2016 terrorist attacks.

\section{An overview of trauma}

The term trauma comes from an ancient Greek word meaning wound or pierce. It was first used to refer to soldiers who suffered injury due to pierced armour [8]. This ancient definition of trauma based on overwhelmed physical defence has similarities with the current understanding of psychological trauma [8]. An understanding of trauma that is based on psychological roots has been formed during a historical process. Herman [9] summarized the historical process in which concept of trauma had changed over time. He indicated that a specific type of psychological trauma has emerged into public awareness over past decades. Hysteria, shell shock (combat neurosis), and sexual and domestic violence attracted public attention over the last hundred years. Hysteria was the first type of psychological trauma that appeared as an important research topic during the last century. Shell shock or combat neurosis was another type of psychological trauma that was recognized as an important topic. The reality of psychological trauma attracted attention again because of negative effect of First World War. Charles Myers introduced the term shell shock to define soldiers' experiences that were similar to hyste- ria. The causes of this syndrome were the emotional stress of warfare. Subsequently, both the Second World War and Vietnam War resulted in increased attention to the psychological effects of war and treatment of psychological trauma. Some soldiers established an anti-war movement and formed rap groups to provide support for veterans and raise awareness about the effects of war. By the agency of anti-war movements and national exposure to the traumatic experience or war, PTSD (Post-traumatic Stress Disorder) was introduced as an official diagnosis in the Diagnostic Statistical Manual of Mental Disorders third version (DSM III) in 1980. The first public speech concerning rape occurred in 1971. Increased attention to women's experience of negative life events made it easier to talk about rape while information about the prevalence rate of sexual abuse became more public. Subsequently, it became clear that psychological effects of rape, incest, and violence on women were similar to the effect of war on men. Soon, in addition to emerging awareness about the effect of war on men, awareness about women's traumatic experience increased [9]. In summary, it seems that the definition of trauma has gradually shifted from involving physical factors to including psychological effects. Today, the psychological effect of traumatic events on people is the focus of several studies.

\section{Traumatic life events}

Traumatic events include a large scope of events such as wars, interpersonal violence, natural disasters, serious illnesses, accidents and the death of a loved one. However, it is important to distinguish traumatic events from other stressful events. Juhant and Zalec (2012) argued that when people are exposed to traumatic events, their ability to integrate their emotions is overwhelmed and they feel a threat to their life, the life of a loved one, or to their bodily integrity [10].

In the DSM III, a traumatic event was defined as a very stressful event outside the range of usual human experience. This definition was criticized for ignoring the way in which an individual makes sense of a traumatic event [8]. According to DSM-IV-TR, traumatic events have two components:

1. Experiencing, witnessing, or confronting actual or threatened death or serious injury, or a threat to the physical integrity of oneself or others;

2. Experiencing intense fear, helplessness or horror.

Some modifications were made in the definition of trauma in DSM V in which a traumatic event is de- 
fined as an event that involves actual or threatened death, a serious injury, or sexual violation. According to DSM V, an individual may personally experience or witness these kinds of events, learn that the traumatic event occurred to a close family member or friend, or may be exposed to repeated or aversive details of the traumatic event. Besides, the peri-traumatic fear, helplessness or horror requirements were eliminated in DSM V. In the present study, participants' self-reporting of an event as traumatic was sufficient to be included in the sample [11].

There have been many findings about the prevalence rate of traumatic events. The lifetime prevalence of exposure to any trauma was $89.6 \%$ in the Detroit, Michigan area [12], 80.8\% in Sweden [13], $76 \%$ for adults in Mexico [14], 80.3\% for young women in Japan [15], 75\% in South Africa [16], and $21.4 \%$ for youths in Munich, Germany. These findings have suggested that the prevalence rate of lifetime exposure to any traumatic events is high [17].

A meta-analysis conducted by Vishnevsky et al. summarized the results of 70 studies, including different populations, such as the USA, Turkey, and China. This study revealed that the most prevalent types of events were cancer, bereavement, terrorism, and natural disasters. It seems that the prevalence of each type of traumatic event may show differences in different populations [18].

In summary, the life-time occurrence of traumatic events is quite high. Thus, most people experience a kind of traumatic event during their lifetime. Therefore, the possible consequences of traumatic events are important.

\section{Post-traumatic stress symptoms}

The effects of traumatic events may vary across individuals. People may experience positive or negative changes after a traumatic event. Some people may experience trauma-related stress in the aftermath of a highly stressful event. The psychological effect of traumatic events has attracted public attention over the last hundred years. Studies about hysteria, the negative effect of world wars and increasing awareness about women's exposure to domestic violence and sexual abuse has attracted public attention to the issue of psychological effects of traumatic experience [9].

Post-traumatic stress disorder (PTSD) was first defined in the DSM III. Some modifications were made in DSM IV and DSM V. According to DSMIV-TR [11], there are three symptom clusters under PTSD diagnostic criteria. These are re-experiencing, avoidance, and hyperarousal. There are 5 symptoms under the re-experiencing symptom cluster. These are recurrent and intrusive memories, recurrent dreams about the event, feeling as if the traumatic event was recurring, psychological distress, and physiological reactions. At least 1 of these 5 symptoms should be present for diagnosis. There are 7 symptoms under the avoidance symptom cluster. These are avoiding trauma-related thoughts, feelings, and trauma-related external reminders, forgetting an important part of the event, showing less interest in significant activities, feeling detached from others, having a restricted range of affect, and a sense of foreshortened future. At least 3 of these 7 symptoms should be present for diagnosis. Finally, there are 5 symptoms under the arousal criteria. These are sleep disturbance, feelings of irritability and anger, difficulty in concentration, an increase in the condition of being vigilant and in one's startle response. At least 2 of these 5 symptoms should be present for diagnosis. In addition to these criteria, the duration of such disturbances should be more than one month, while the disturbance should result in significant stress and functional impairment in social, occupational or other important areas of functioning [11].

Three symptom clusters in the DSM-IV has been modified into four symptom clusters in DSM V. Symptom clusters in DSM $V$ are intrusion symptoms (one required), avoidance symptoms (one required), negative alterations in cognitions and mood (two required), and alterations in arousal and reactivity (two required) [19]. A person who meets the symptom requirements in each of the symptom clusters may be diagnosed with PTSD. These diagnostic restrictions imposed by the DSM have led some researchers to examine post-traumatic stress symptoms in the absence of PTSD diagnosis. Terms such as partial PTSD [20], subsyndromal PTSD [21], or subthreshold PTSD [22] are used to refer to non-clinical post-traumatic stress symptoms. Moreover, some researchers are interested in post-traumatic stress symptomatology (PTSS) only to assess total scores of symptoms of avoidance, hyperarousal, and re-experiencing. The way PTSD is defined also affects the prevalence rate of PTSD [23].

Stein et al. defined partial PTSD as having at least one symptom in each symptom cluster category and found that $3.4 \%$ of women and $0.3 \%$ of men were diagnosed with partial PTSD among 1002 people in Canada [20]. Moreover, $2.7 \%$ of women and 1.2\% 
of men were diagnosed with full PTSD. Another study defined partial PTSD as meeting the diagnostic criteria for 2 out of 3 symptom clusters in DSM-IV, finding that among 39 breast cancer survivors, 18\% meet the criteria for full PTSD and 56\% met criteria for partial PTSD [24]. In addition, Marshall et al. showed that $9 \%$ of participants met the full criteria for PTSD. Moreover, $18.9 \%$ of the participants without PTSD diagnosis reported at least one PTSD symptom lasting at least one month after a traumatic event [22].

The prevalence rate of post-traumatic stress symptoms also vary based on demographic variables such as gender, mental health status, and socioeconomic status (SES). It has been shown that although men report more lifetime trauma exposure women report more PTSD symptoms [14, 24, 25]. Kessler et al. proposed that gender difference could be related with the kinds of trauma experienced. They indicated that the probability of PTSD varied according to the nature of the traumatic event. They showed that men who experienced combat, childhood neglect, and childhood physical abuse, and women who experienced sexual molestation, physical attack, threat with a weapon, and childhood physical abuse were more likely to develop PTSD. In addition, they showed that women were more likely to experience the kinds of trauma that result in PTSD. They discussed that more women showed PTSD symptoms than men, because women experienced traumatic events that were more likely to result in PTSD [25]. Frans et al., however, found that controlling for the trauma type did not account for gender differences in PTSD rates and argued that women may be more vulnerable to stress [13].

The probability of developing PTSD symptoms is also affected by trauma related factors. Previous findings showed that a threat to life during trauma physical injury [26], and peritraumatic dissociation were positively associated with developing post-traumatic stress response [27].

Furthermore, trauma type has an effect on the probability of developing PTSD symptoms. It has been suggested that sexual assault is more likely to result in PTSD compared to other types of traumatic events $[24,25]$. In addition, Breslau et al. showed that experiencing human-made trauma such as rape, torture, and violence is more likely to result in PTSD compared to unintentional violence or learning about traumatic events experienced by others [12].
Moreover, the number of the lifetime trauma exposures has been studied in PTSD literature. Prior traumatic life experience increases the probability of PTSD [28]. Similarly, according to the results of a 30year longitudinal study, in addition to the strong association between the severity of PTSD symptoms and the number of lifetime trauma exposures, there was also a strong linear relationship between PTSD symptom severity and significant negative life events, such as being robbed (without physical confrontation), a major relationship break-up, and major financial problems [29].

Finally, the effect of time elapsed since the traumatic event has been investigated. Research findings have suggested that PTSD symptoms decline as time passes [30]. Amir et al. found that there was an increase in PTSD symptoms among individuals who experienced various types of trauma as time elapsed since the trauma. They argued that a positive correlation between time elapsed since the trauma and PTSD symptoms might be a sample artefact. They proposed that participants with a history of war experienced their trauma several years earlier and their PTSD symptoms increased as time elapsed since the trauma and seemed to be chronic. This sample characteristic might lead to a significant positive correlation between PTSD symptoms and the time since the trauma [24].

It seems that the probability of developing PTSD symptoms is affected by demographic variables and trauma related factors. It is important to point out that while people do not always develop trauma related stress, they may even show trauma-related positive change.

\section{METHOD}

Since the hospital is in a neighbouring the street to where terror attacks occurred, all healthcare professionals $\geq 18$ years of age who were on duty that night in the Dr. Ridvan Ege Training and Research Hospital and were auditory or visual witnesses of the event were included in the study as the first group while healthcare professionals who work in the same hospital but were not on duty that night were included as the control group.

The second group is the control group of our study. Data forms were given to the participants by a psychologist visiting their work place. No psychiatric interview was conducted with the participants. 


\section{Statistic}

The SPSS 15 statistical program was used for conducting a statistical analysis of the data. The Kolmogorov-Smirnov test was performed for the normality test of the data. Because all variables were normally distributed, the t-test was used in the intergroup comparisons. The Chi-square test was used for the analysis of two categorical variables.

\section{Data collection forms}

- Sociodemographic data form: Participants' demographics such as age and gender were noted.

- The Post-traumatic Stress Diagnostic Scale (PDS): PTSD symptom severity which includes 17 questions regarding PTSD symptoms. Each question is rated on a 4-point scale. Responses range from 0 (not at all or only one time) to 3 (five or more times a week/almost always). Post-traumatic Stress Disorder was based on diagnostic criteria. The ratio of the lower scale is $0-51$. The higher score indicates that the person is adversely affected and shows signs of post-traumatic stress. If the stress symptom score is 10 or less, it is mild; between 11 and 20, moderate-severe between 21 and 35; and serious above 35 [31]. This part has three subscales based on DSM-IV criteria for PTSD: re-experiencing, avoidance and hyper-arousal. It was reported that the internal consistency of the 17-item PTSD severity subscale was 92 , while the test-retest reliability coefficient was 0.83 . Moreover, Foa et al. checked the concurrent validity of PTSD symptom severity scores with other measures of trauma related psychopathology [31].

The PDS was adapted into Turkish version by Isikli [32]. He reported that the internal consistency of the 17-item PTSD severity subscale was 93 . Moreover, the responses for the 17 items of the PTSD severity subscale were subjected to factor analysis. Three factor-solutions were obtained and explained 59\% of the variance. Isikli [32] reported the psychometric properties of the Turkish version as satisfactory.

In the present study, the PDS was used to examine lifetime experiences of various types of traumatic events (the first part of the PDS). Furthermore, the PDS was used to identify the most distressing event, and determining the time of the event (a section from the second part of the PDS). Finally, the PDS was used to measure PTSD symptom severity. PTSD symptom severity scores were obtained by summing the scores of post-traumatic symptoms. PTSD severity scores were used to operationalize ongoing psychological effects of the traumatic event on the participants. The fourth part of the PDS was not included in the study. The alpha coefficient of PTSD symptom severity subscale was 0.94 for the present study [32].

\section{RESULTS}

In our study, there were two groups: healthcare professionals in charge of the hospital on July 15, 2016 (First Group) and healthcare professionals (control group) not in the hospital that night. There were 45 participants in the first group and 45 in the control group of our post-FETO terrorist attack scale study. Of our participants, 45.6\% (41) were female and $54.4 \%$ (49) were male. The average age of the first group was $27.60 \pm 3.353$. The average age of the control group was $28.69 \pm 3.878$. There was no statistically significant difference between groups in terms of gender $(p>0.05)$ (Tab. 1). The groups have a statistically normal distribution in terms of gender.

The mean post-traumatic diagnostic scale stress score of the control group was 11.87. The mean post-traumatic diagnostic scale stress score of Group 1 was 21.91 (Tab. 2). There was no significant difference in age between the groups $(p>0.05)$ (Tab. 3). There was a significant difference between the groups in terms of their post-traumatic diagnostic scale stress score $(p<0.05)$ (Tab. 3). While the healthcare professionals on duty on July 15, 2016 (Group 1) had moderate-severe $(21.91 \pm 5.11)$ stress disorder, the healthcare professionals who were not at the hospital on July 15 , 2016 (Control Group) had moderate stress disorder $(11.87 \pm 6.86)$

\begin{tabular}{|l|l|c|c|c|}
\hline \multicolumn{2}{|c|}{ Table 1. Gender distribution between groups } \\
\cline { 2 - 4 } \multicolumn{2}{|c|}{} & $\begin{array}{c}\text { Groups } \\
\text { Control } \\
\text { Group }\end{array}$ & Group 1 & \multirow{2}{*}{ Total } \\
\hline \multirow{2}{*}{ Gender } & Female & $20(48.8 \%)$ & $21(51.2 \%)$ & 41 \\
\cline { 2 - 4 } & Male & $25(51 \%)$ & $24(49 \%)$ & 49 \\
\hline \multirow{2}{*}{ Total } & $45(50 \%)$ & $45(50 \%)$ & 90 \\
\hline
\end{tabular}

Group 1 - healthcare professionals who were on duty at that night, Control Group - healthcare professionals who work in the same hospital but were not on duty at that night 
Table 2. Post-traumatic stress score and age of the groups

\begin{tabular}{|l|l|c|c|c|}
\hline & Group & N & Mean & Std. Deviation \\
\hline \multirow{3}{*}{ Total } & Control & 45 & 11.87 & 6.854 \\
\cline { 2 - 5 } & Group 1 & 45 & 21.91 & 5.112 \\
\hline \multirow{2}{*}{ Age } & Control & 45 & 28.69 & 3.878 \\
\cline { 2 - 5 } & Group 1 & 45 & 27.60 & 3.353 \\
\hline
\end{tabular}

\begin{tabular}{|c|c|c|}
\hline \multicolumn{3}{|c|}{ Sig. (2-tailed) } \\
\hline \multirow[t]{2}{*}{ PTSD } & Equal variances assumed & 0.000 \\
\hline & Equal variances not assumed & 0.000 \\
\hline \multirow[t]{2}{*}{ Age } & Equal variances assumed & 0.158 \\
\hline & Equal variances not assumed & 0.158 \\
\hline
\end{tabular}

Table 4. T-test for Equality of Means between men and women in Group 1

\begin{tabular}{|l|l|l|}
\hline \multicolumn{3}{|c|}{ Sig. (2-tailed) } \\
\hline \multirow{2}{*}{ PTSD } & Equal variances assumed & 0.025 \\
\cline { 2 - 3 } & Equal variances not assumed & 0.026 \\
\hline
\end{tabular}

There was no statistically significant difference between the genders in terms of post-traumatic stress disorder in the control group ( $p>0.05)$. The mean PTSD score was $12.50 \pm 7.515$ for women who were not at the hospital, while the mean PTSD was $11.36 \pm 6.389$ for men who were not at the hospital.

There was a statistically significant difference between the sexes in terms of post-traumatic stress disorder in Group $1(p<0.05)$. The mean PTSD score was $23.71 \pm 5.031$ in women who were at the hospital, while the mean PTSD score in men who were at the hospital was $20.33 \pm 4.733$ (Tab. 4). In Group 1, post-traumatic stress disorder was moderate in men while women were deemed moderately severe.

\section{DISCUSSION}

In the studies conducted after terrorist attacks carried out by bombing, it reported that being physically injured is a risk factor for the development of PTSD $[6,33]$. Among the healthcare professionals on duty on the night of the attack, the median-severe stress disorder rate was found to be $65 \%$, and the severity of stress disorder at $2.5 \%$. Studies conducted after the terrorist attacks reported high PTSD rates of $7 \%$ to $35 \%$ among the population $[2,6,7]$.
The characteristics of the samples studied may be an important factor that makes the difference between the rates of PTSD determined in studies. For example; Gabriel et al. reported a PTSD rate of $44.1 \%$ in the physically injured group and a PTSD rate of $12.3 \%$ among nearby residents after the bombing attack in Madrid on 11 March 2004 [7]. However, this variability is difficult to explain with only a variety of methodological differences. Many factors can change the prevalence of the condition, such as the destruction caused by the traumatic events, the loss of life and the time of the study [34]. We can relate to the fact that this rate is higher in our study as those involved were very close to the central hospital where the events took place and could hear the heavy gunfire which lasted all night until daytime. We think that the healthcare personnel comprise a specialized group as, in addition, taking care of injured persons may cause secondary trauma. Thus, healthcare professionals underwent two traumas at one time.

In our study, PTSD evaluations were statistically significant compared to healthcare personnel who were on duty at the hospital and out-of-hospital health personnel, with the average PTSD score of the first group being evaluated as moderate-severe stress disorder. The death of someone in close proximity due to an explosion or visually witnessing the explosion showed association with the development of PTSD in studies on terrorist attacks $[6,7]$. This situation may be related to the fact that the health personnel working in the hospital in our study had more exposure to audiovisual and visual psychological trauma due to the proximity of the hospital to the conflict area and also the injuries and deaths seen in the hospital which can be found in the literature. The PTSD point score of the control group in our study was moderate. We can explain this by their exposure to visual trauma after watching the events of that night in the media. In our study, due to the fact that both study groups are composed of healthcare personnel, the difference between the two groups in terms of stress disorder is interpreted as the personnel working at the hospital were exposed to secondary trauma due to the patients who were presented for diagnosis and treatment at the hospital that night. We have not yet found a study in the literature that measures primary and secondary traumatic stress disorder experienced by healthcare professionals related to this topic. Despite our unique study, we think that we need more 
such studies to shed light on the stress disorders that may be experienced by healthcare personnel in the future.

\section{CONCLUSION}

Despite the fact that there have been studies conducted in the previous years after terrorist bombing attacks, the FETO terrorist attack in our study was of a different from other bombings as Turkey's democratic system was the target. Therefore, there is no data in the literature concerning a study involving a terrorist activity such as ours, nor could we find any studies regarding healthcare personnel in the literature. This situation makes our study unique. Our country is at risk from the fact that such attacks may be experienced again because of its unique conditions. The results of our work support the data concerning the high level of exposure to PTSD when one is exposed to a terrorist attack. For this reason, the identification of the characteristics of pre-traumatic healthcare individuals at risk is useful in planning the introduction of preventive and curative health services. At the same time, there is a need for longer-term work and broader samples in order to reveal the psychological consequences of such attacks.

Conflict of interest: None declared.

\section{REFERENCES}

1. Everly GS, Mitchell JT. America under attack: the "10 commandments" of responding to mass terrorist attacks. Int J Emerg Ment Health. 2001; 3(3): 133-135, indexed in Pubmed: 11642190.

2. Galea S, Nandi A, Vlahov D. The epidemiology of post-traumatic stress disorder after disasters. Epidemiol Rev. 2005; 27: 78-91, doi: 10.1093/epirev/mxi003, indexed in Pubmed: 15958429.

3. Norris FH, Friedman MJ, Watson PJ, et al. 60,000 disaster victims speak: Part I. An empirical review of the empirical literature, 1981-2001. Psychiatry. 2002; 65(3): 207-239, indexed in Pubmed: 12405079.

4. Gidron Y. Posttraumatic stress disorder after terrorist attacks: a review. J Nerv Ment Dis. 2002; 190(2): 118-121, indexed in Pubmed: 11889367.

5. North CS, Nixon SJ, Shariat S, et al. Psychiatric disorders among survivors of the Oklahoma City bombing. JAMA. 1999; 282(8): 755-762, indexed in Pubmed: 10463711.

6. Njenga FG, Nicholls PJ, Nyamai C, et al. Post-traumatic stress after terrorist attack: psychological reactions following the US embassy bombing in Nairobi: Naturalistic study. Br J Psychiatry. 2004; 185: 328333, doi: 10.1192/bjp.185.4.328, indexed in Pubmed: 15458993.
7. Gabriel R, Ferrando L, Cortón ES, et al. Psychopathological consequences after a terrorist attack: an epidemiological study among victims, the general population, and police officers. Eur Psychiatry. 2007; 22(6): 339-346, doi: 10.1016/j.eurpsy.2006.10.007, indexed in Pubmed: 17227706.

8. Tummey R, Turner T. Critical Issues in Mental Health. Palgrave, Basingstoke 2008.

9. Herman J. Trauma and Recovery. Basic Books, New York 1997.

10. Juhant J, Zalec B. Reconciliation: The Way of Healing and Growth. LIT, Zurich, Münster 2012.

11. American Psychiatric Association (APA). Diagnostic and statistical manual of mental disorders (4th ed., text rev.) Washington, 2000.

12. Breslau N, Kessler RC, Chilcoat HD, et al. Trauma and posttraumatic stress disorder in the community: the 1996 Detroit Area Survey of Trauma. Arch Gen Psychiatry. 1998; 55(7): 626-632, indexed in Pubmed: 9672053.

13. Frans 0 , Rimmö $P A$, Aberg $L$, et al. Trauma exposure and post-traumatic stress disorder in the general population. Acta Psychiatr Scand. 2005; 111(4): 291-299, doi: 10.1111/j.1600-0447.2004.00463.x, indexed in Pubmed: 15740465.

14. Norris FH, Murphy AD, Baker CK, et al. Epidemiology of trauma and posttraumatic stress disorder in Mexico. J Abnorm Psychol. 2003; 112(4): 646-656, doi: 10.1037/0021-843X.112.4.646, indexed in Pubmed: 14674876.

15. Mizuta I, Ikuno T, Shimai S, et al. The prevalence of traumatic events in young Japanese women. J Trauma Stress. 2005; 18(1): 33-37, doi: 10.1002/jts.20001, indexed in Pubmed: 16281193.

16. Williams SL, Williams DR, Stein DJ, et al. Multiple traumatic events and psychological distress: the South Africa stress and health study. J Trauma Stress. 2007; 20(5): 845-855, doi: 10.1002/jts.20252, indexed in Pubmed: 17955545.

17. Perkonigg A, Kessler RC, Storz S, et al. Traumatic events and post-traumatic stress disorder in the community: prevalence, risk factors and comorbidity. Acta Psychiatr Scand. 2000; 101(1): 46-59, indexed in Pubmed: 10674950.

18. Vishnevsky T, Cann A, Calhoun L, et al. Gender Differences in Self-Reported Posttraumatic Growth: A Meta-Analysis. Psychology of Women Quarterly. 2010; 34(1): 110-120, doi: 10.1111/j.14716402.2009.01546.x.

19. American Psychiatric Association (APA). Diagnostic and statistical manual of mental disorders (4th ed., text rev.) Washington, 2013.

20. Stein MB, Walker JR, Hazen AL, et al. Full and partial posttraumatic stress disorder: findings from a community survey. Am J Psychiatry. 1997; 154(8): 1114-1119, doi: 10.1176/ajp.154.8.1114, indexed in Pubmed: 9247398.

21. Bryant RA, Harvey AG. Delayed-onset posttraumatic stress disorder: a prospective evaluation. Aust N Z J Psychiatry. 2002; 36(2): 205-209, doi: 10.1046/j.1440-1614.2002.01009.x, indexed in Pubmed: 11982541.

22. Marshall RD, Olfson M, Hellman F, et al. Comorbidity, impairment, and suicidality in subthreshold PTSD. Am J Psychiatry. 2001; 158(9): 1467-1473, doi: 10.1176/appi.ajp.158.9.1467, indexed in Pubmed: 11532733. 
23. Muller RT, Sicoli LA, Lemieux KE. Relationship between attachment style and posttraumatic stress symptomatology among adults who report the experience of childhood abuse. J Trauma Stress. 2000; 13(2): 321-332, doi: 10.1023/A:1007752719557, indexed in Pubmed: 10838678.

24. Amir M, Ramati A. Post-traumatic symptoms, emotional distress and quality of life in long-term survivors of breast cancer: a preliminary research. J Anxiety Disord. 2002; 16(2): 195-206, indexed in Pubmed: 12194544.

25. Kessler RC, Sonnega A, Bromet E, et al. Posttraumatic stress disorder in the National Comorbidity Survey. Arch Gen Psychiatry. 1995; 52(12): 1048-1060, indexed in Pubmed: 7492257.

26. Kilpatrick D, Saunders B, Amick-McMullan A, et al. Victim and crime factors associated with the development of crime-related post-traumatic stress disorder. Behavior Therapy. 1989; 20(2): 199-214, doi: 10.1016/s0005-7894(89)80069-3.

27. Breh DC, Seidler GH. Is peritraumatic dissociation a risk factor for PTSD? J Trauma Dissociation. 2007; 8(1): 53-69, doi: 10.1300/ J229v08n01_04, indexed in Pubmed: 17409054.

28. Bremner JD, Southwick SM, Johnson DR, et al. Childhood physical abuse and combat-related posttraumatic stress disorder in Vietnam veterans. Am J Psychiatry. 1993; 150(2): 235-239, doi: 10.1176/ ajp.150.2.235, indexed in Pubmed: 8422073.

29. Mulder R, Fergusson D, Horwood J. Post-traumatic stress disorder symptoms form a traumatic and non-traumatic stress response dimension. Aust N Z J Psychiatry. 2013; 47(6): 569-577, doi: 10.1177/0004867413484367, indexed in Pubmed: 23539639.

30. Mayou RA, Ehlers A, Bryant B. Posttraumatic stress disorder after motor vehicle accidents: 3-year follow-up of a prospective longitudinal study. Behaviour Research and Therapy. 2002; 40(6): 665-675, doi: 10.1016/s0005-7967(01)00069-9.

31. Foa $E$, Cashman $L$, Jaycox $L$, et al. The validation of a self-report measure of posttraumatic stress disorder: The Posttraumatic Diagnostic Scale. Psychological Assessment. 1997; 9(4): 445-451, doi: 10.1037//1040-3590.9.4.445.

32. Isikli S. Travma Sonrası Stres Belirtileri olan bireylerde olaya ilişkin dikkat yanlıı̆̆ı, ayrışma düzeyi ve çalışma belleği uzamı arasındaki ilişkiler. Yayınlanmamış Doktora Tezi. Hacettepe Üniversitesi Psikoloji Bölüm, Ankara 2006.

33. Verger $P_{1}$ Dab $W$, Lamping $D L$, et al. The psychological impact of terrorism: an epidemiologic study of posttraumatic stress disorder and associated factors in victims of the 1995-1996 bombings in France. Am J Psychiatry. 2004; 161(8): 1384-1389, doi: 10.1176/ appi.ajp.161.8.1384, indexed in Pubmed: 15285963.

34. Başoğlu M, Salcioğlu E, Livanou M. Traumatic stress responses in earthquake survivors in Turkey. J Trauma Stress. 2002; 15(4): 269-276, doi: 10.1023/A:1016241826589, indexed in Pubmed: 12224798. 